\title{
THE EFFECTS OF PHOTOPERIOD AND A TRYPANOSOMA BRUCEI GAMBIENSE INFECTION ON THE REPRODUCTIVE ORGANS OF MALE MICROTUS MONTANUS
}

\author{
PORTIA U. ASHMAN* AND J. R. SEED $\dagger$ \\ *Department of Biology, Xavier University of Louisiana, Nerw Orleans, Louisiana 70125, \\ and $\dagger$ Department of Biology, Tulane University, New Orleans, Louisiana 70118, U.S.A.
}

(Received 21st September 1973)

\begin{abstract}
Summary. The effects of photoperiod and a Trypanosoma brucei gambiense infection on the gonads of male Microtus montanus were studied. Uninfected males kept in constant light had significantly heavier testes than males kept in constant darkness. Infected voles kept under 12-hr light/12-hr dark or constant darkness had significantly smaller testes than the uninfected animals kept under identical lighting regimens. Infected males kept in constant light, however, maintained normal testicular weights, demonstrating that photoperiod conditions can modify the results of infection. In addition, it was shown that the trypanosomes have a predilection for the testes of Microtus montanus and accumulate in these organs in large numbers 15 days after intraperitoneal inoculation. Possible reasons for the predilection of the trypanosomes for the testes of mammals are discussed.
\end{abstract}

\section{INTRODUCTION}

Certain pathogenic organisms are known to have a predilection for the testes of some mammalian hosts, e.g. the mumps virus causes orchitis, degeneration of the epithelium of the seminiferous tubules, serofibrinous exudate, congestion and punctate haemorrhages in the interstitial tissue (Davis, Dulbecco, Eisen, Ginsberg \& Wood, 1967). Treponema pallidum becomes established in the testes of rabbits when injected either intratesticularly or intravenously (Uhlenhuth \& Mulzer cited by Uhlenhuth \& Emmerich, 1913). The TG 83 strain of the Venezuelan encephalitis (VE) virus infects hamster testes only if the virus is injected intratesticularly (Vestergaard \& Scherer, 1971). This virus causes orchitis, cytonecrosis, decrease in the number of germinal cells, atrophy, fibrosis and eventual sterility. Other organisms causing orchitis are Mycobacterium tuberculosis and the smallpox virus.

In addition to viruses and bacteria, some animal parasites have a predilection for the testes of certain mammals. The filiarial nematode, Wuchereria bancrofti, can cause enlargement of the testes in humans, while Trypanosoma evansi equiperdum of horses is transmitted during copulation. This trypanosome 
can cause ulceration of the gonads of both male and female horses. Uhlenhuth \& Emmerich (1913) found that sleeping sickness and dourine trypanosomes accumulated in large numbers in the testes of rabbits 8 to 13 days after injection intratesticularly, intravenously or intraperitoneally. Several other investigators have used this testicular technique for the diagnosis of trypanosomes (Ciuca, 1933; Domilescu, 1938; Soldini, 1939). Successful transmission of the South African strain of dourine to the rabbit testis and splenectomized rat was accomplished by Haig \& Lund (1948). More recently, Heisch, KillickKendrick, Guy \& Dorrell (1970) inoculated different species of Trypanosoma and Leishmania directly into the testicles of rabbits, guinea-pigs, hamsters and rats. They found that the trypanosomes grew well in these organs, causing inhibition of spermatogenesis, atrophy of the tubules, interstitial fibrosis and round cell infiltration.

Molyneaux (1972) isolated Trypanosoma brucei gambiense from unspecified human glandular material and produced testicular infections in rabbits. The trypanosomes could be detected 16 days after the inoculation. By using the intratesticular inoculation technique, it was possible to maintain the trypanosomes in individual animals for many months.

We have been investigating Trypanosoma brucei gambiense infections in an outbred population of voles, Microtus montanus. Approximately $22 \%$ of the infected animals raised from an outbred colony developed a type of infection similar to African sleeping sickness found in man (Seed \& Negus, 1970). In Microtus and man, the disease is chronic, exhibiting neurological symptoms and low parasitaemia in the peripheral blood. Chronically infected Microtus may remain in a lethargic state for days showing activity only when physically disturbed (Seed \& Negus, 1970). Autopsy material from chronically infected males always contained large numbers of live trypanosomes in both testes even though inoculation was intraperitoneal rather than intratesticular.

Uninfected and infected animals have been maintained under various photoperiod regimens (Ashman \& Seed, 1973a, b). Pinter (1968) demonstrated that male $M$. montanus kept under 18-hr light developed heavier testes than those animals under $6 \mathrm{hr}$ light. We therefore decided to investigate the effects of both photoperiod and a chronic $T . b$. gambiense infection on the gonads of male $M$. montanus.

\section{MATERIALS AND METHODS}

The animals used in this investigation were the descendants of a wild stock of Microtus montanus trapped live in 1960 at the Jackson Hole Biological Station, Moran, Wyoming. Since that time, they have been maintained at Tulane University (Pinter \& Negus, 1965).

To ensure that the colony remained outbred, genealogical records were kept for all mating pairs and their offspring. All voles were weaned at approximately 3 weeks of age, numbered by toe clipping, separated according to sex and pooled in large tubs. The floor of the tubs and cages was covered with sawdust and cotton batting was used for bedding (Ashman \& Seed, 1973a). Purina Rabbit Chow and tap water were given freely with weekly supplements 
of fresh lettuce. All the animals (167 males) were between 4 and 7 weeks of age at the beginning of the experiments. They were selected at random from the pooling tubs and subsequently maintained under the various photoperiod regimens. The age of the animals at death and the length of time under a particular regimen varied for each experiment. The length of treatment and ages are given in the results. Three or four voles were placed in each cage unless stated otherwise.

The Wellcome TS strain of Trypanosoma brucei gambiense used in this investigation is considered a subspecies of Trypanosoma brucei brucei. This strain was isolated from a patient in 1921 and has since been maintained in 20-g white mice by syringe passage every 2nd day (Seed, Baquero \& Duda, 1965).

Blood trypanosomes were harvested from mice using the method of Seed \& Gam (1966). The mice were bled at peak parasitaemia by heart puncture using $1 \%$ sodium citrate $(\mathrm{w} / \mathrm{v})$ as the anticoagulant. The trypanosome suspension was then centrifuged at $500 \mathrm{~g}$ for $4 \mathrm{~min}$ in an International Clinical Centrifuge. After centrifugation, the serum layer and trypanosome layer were removed. The trypanosome layer was resuspended in Ringer phosphate $(0.1 \mathrm{M}-\mathrm{NaCl}$, $0.06 \mathrm{M}-\mathrm{KCl}, 0.02 \mathrm{M}-\mathrm{MgSO}_{4}$ and $0.025 \mathrm{M}$-phosphate buffer, $\mathrm{pH} \mathrm{7.2,} \mathrm{containing}$ $0.01 \mathrm{~m}$-glucose) and was recentrifuged at $1200 \mathrm{~g}$ for $4 \mathrm{~min}$. The trypanosomes were then resuspended in glucose-Ringer phosphate at a concentration of nine trypanosomes per high-power field (HPF) (approximately 5.0 $\times 10^{6}$ trypanosomes $/ \mathrm{ml}$ ).

Male $M$. montanus were injected intraperitoneally with $0.5 \mathrm{ml}$ of this suspension, i.e. about $2.5 \times 10^{6}$ trypanosomes. After infecting the animals, the inoculum was re-checked for live trypanosomes.

Animals used in the photoperiod experiments were housed in one of two locations: (1) an isolated environmental chamber maintained at an ambient temperature of approximately $18 \pm 3 \cdot 5^{\circ} \mathrm{C}$ and a luminance of 43 to $685 \mathrm{~cd} / \mathrm{m}^{2}$; (2) in the general animal quarters maintained at an ambient temperature of approximately $18 \pm 2 \cdot 5^{\circ} \mathrm{C}$ and a luminance of 86 to $685 \mathrm{~cd} / \mathrm{m}^{2}$.

At the end of the experiments, the animals were killed by chloroform and, after weighing, the livers were removed and the carcass was stored in alcoholformalin-acetic acid (AFA). At a later date, the gonads were cleared of all fatty tissue and stored in AFA. The gonads (testes plus epididymides) were weighed on a Mettler $\mathrm{H}-10$ balance to the nearest $0.1 \mathrm{mg}$. The testes of infected animals included in the Tables of gonadal weights were not examined for live trypanosomes. Statistical analyses included standard errors of the means and the twosample $t$ test between the means. The level of significance chosen for all of the statistical tests was the $5 \%$ level.

Microtus montanus raised in the laboratory attain heavier gonadal weights with increasing age (Pinter, 1968). In our laboratory-bred colony of $M$. montanus, the older animals became heavier than younger voles. In this investigation, therefore, gonadal weights were normalized (ratio of gonadal weight/body weight) and were included in the Tables. Because the infected animals were always considerably heavier than the uninfected animals due to the accumulation of excess body fluid, however, only the actual reproductive weights (paired testes and epididymides) are discussed. The increased weight would 
have given biased results in favour of smaller gonads for the infected voles. In addition to the data on the reproductive organs of male $M$. montanus, the adrenal glands and spleens were also removed, stored in fixative and weighed. The relationships between adrenal glands, gonads and spleens will be reported at a later date.

In order to determine the presence of trypanosomes and spermatozoa in the testes and epididymides, these organs were removed from some of the animals at autopsy and placed in 70\% alcohol to kill any possible externally contaminating trypanosomes covering the surface of the testes. After blotting and drying, the organs were placed in either phosphate-buffered saline, $\mathrm{pH} 7 \cdot 2$, or in glucose-Ringer phosphate, cut open and a small portion of the contents was smeared on a slide. The presence of trypanosomes was determined and graded as $1^{+}$( 1 to $\left.20 / \mathrm{HPF}\right), 2^{+}$(20 to $40 / \mathrm{HPF}$ ), $3^{+}$(40 to 60/HPF), and $4^{+}$(over $60 / \mathrm{HPF})$. Presence $(+)$ or absence $(-)$ of spermatozoa was recorded.

Table 1. Effects of photoperiod on the weights of paired testes and epididymides of uninfected male Microtus montanus

\begin{tabular}{|c|c|c|}
\hline & Actual weight $(m g)$ & $\begin{array}{l}\text { Normalized weight } \\
\text { (gonadal wt in } \mathrm{gl} \\
\text { body wt in } \mathrm{g}) \times 10^{-3}\end{array}$ \\
\hline $\begin{array}{l}\text { Constant light } \\
\text { Constant dark }\end{array}$ & $\begin{array}{l}325 \cdot 62 \pm 31 \cdot 60 \quad(9) \\
125 \cdot 59 \pm 27 \cdot 27(13)\end{array}$ & $\begin{array}{l}7.76 \pm 0.08 \quad(8) \\
3.34 \pm 0.67(13)\end{array}$ \\
\hline Significance & $P<0.01$ & $P<0.01$ \\
\hline
\end{tabular}

Figures in parentheses represent the number of animals which were 8 to 10 weeks old at the time of death and had been kept in the isolated environmental chamber for 32 days.

Each experiment should be considered independently from any other because the animals were treated at different times of the year and were different ages. Each single experiment in constant light or constant darkness or with infected versus uninfected animals, however, was carried out at the same time under identical conditions.

\section{RESULTS}

\section{Reproductive tract weights (paired testes with epididymides)}

The first set of experiments involved two groups of uninfected $M$. montanus kept in two isolated environmental chambers for about 32 days depending on the time of death. This varied from 8 to 10 weeks of age. One group of nine males was maintained in one cage under constant lighting, and the other group of thirteen males was kept in one cage under constant darkness. Table 1 demonstrates that males in constant light had significantly $(P<0.01)$ heavier testes than males kept in constant darkness.

Another group of thirty-seven males was kept, three voles per cage, in the general animal quarters under $12 \mathrm{hr}$ light/12 hr dark for 70 days (Table 2). Twenty-five of the animals were infected for 22 days before they were killed at approximately 13 weeks of age. The infected males had smaller testes $(P<0 \cdot 10)$ than the uninfected males (Table 2). Even though this difference is not statistically significant at the $5 \%$ level, it does suggest a trend. 
In another experiment involving seventy-five males, the effects of both a T. b. gambiense infection and photoperiod were considered (Table 3 ). The voles were kept three per cage either in the general animal quarters in constant light or in the isolated environmental chambers in constant darkness. After 22 days, fifty voles were infected with the same inoculum of trypanosomes. These animals were approximately 12 weeks old at the time of death. (Lack of space precluded having a third group under 12-hr light/12-hr dark at the same time.) Table 3 shows that both uninfected and infected animals maintained in constant darkness had significantly smaller testes $(P<0.01)$ than those animals kept under constant light. In addition, the infected males kept in constant

Table 2. The effects of a Trypanosoma brucei gambiense infection on the weights of paired testes and epididymides of male Microtus montanus kept in 12-hr light/12hr dark

\begin{tabular}{|c|c|c|}
\hline & Actual weight $(m g)$ & $\begin{array}{l}\text { Normalized weight } \\
\text { (gonadal wt in } g / \\
\text { body wt in } g) \times 10^{-3}\end{array}$ \\
\hline $\begin{array}{l}\text { Uninfected males } \\
\text { Infected males } \\
\text { Significance }\end{array}$ & $\begin{array}{c}190 \cdot 8 \pm 28.57(18) \\
136 \cdot 1 \pm 14.96(19) \\
P<0 \cdot 10\end{array}$ & $\begin{array}{c}4.81 \pm 0.58(18) \\
3.01 \pm 0.37(19) \\
P<0.02\end{array}$ \\
\hline
\end{tabular}

Figures in parentheses represent the number of animals which were approximately 13 weeks old at the time of death; they were kept in the isolated environmental chamber for 70 days.

Table 3. Effects of a Trypanosoma brucei gambiense infection and photoperiod on the reproductive tract weights of male Microtus montanus

\begin{tabular}{|c|c|c|c|c|c|c|}
\hline & \multicolumn{3}{|c|}{$\begin{array}{l}\text { Actual wt of paired testes and } \\
\text { epididymides }(m g)\end{array}$} & \multicolumn{3}{|c|}{$\begin{array}{l}\text { Normalized wt (wt of paired testes and } \\
\text { epididymides in } \mathrm{g} / \text { body } w \text { in } \mathrm{g}) \times 10^{-3}\end{array}$} \\
\hline & Constant light & Constant dark & Significance & Constant light & Constant dark & Significance \\
\hline Uninfected & $\begin{array}{c}453 \cdot 4+24 \cdot 18 \\
(17)\end{array}$ & $\begin{array}{c}300 \cdot 5 \pm 38.99 \\
(16)\end{array}$ & $P<0.01$ & $\underset{(17)}{9 \cdot 49 \pm 0 \cdot 56}$ & $\begin{array}{c}5 \cdot 89 \pm 0.56 \\
(16)\end{array}$ & $P<0.01$ \\
\hline Infected & $\begin{array}{c}464 \cdot 6 \pm 30 \cdot 59 \\
(20)\end{array}$ & $\begin{array}{c}166 \cdot 5 \pm 20 \cdot 93 \\
(22)\end{array}$ & $P<0.01$ & $\begin{array}{c}7.99 \pm 0.52 \\
(20)\end{array}$ & $\begin{array}{c}3 \cdot 19 \pm 0 \cdot 36 \\
(22)\end{array}$ & $P<0.01$ \\
\hline Significance & $\begin{array}{c}\text { Not } \\
\text { significant }\end{array}$ & $P<0.01$ & & $P<0.02$ & $P<0.01$ & \\
\hline
\end{tabular}

Figures in parentheses represent the number of animals which were approximately 12 weeks old at the time of death; they were kept in the isolated environmental chamber for 46 days.

darkness had significantly smaller testes $(P<0.01)$ than uninfected males kept in constant darkness (Table 3 ). This reduced weight was the same as the result obtained for uninfected and infected males kept in 12-hr light/12-hr dark (Table 2). Significant differences in actual gonadal weights were not found even at the $10 \%$ level for uninfected and infected males kept in constant light (Table 3).

\section{Presence of trypanosomes in the testes}

In another group of seventeen males infected after 19 days and maintained 
under 12-hr light/12-hr dark, all the testes examined had large numbers of trypanosomes present (60 to $100 / \mathrm{HPF}$ ), a constant finding in the testes of chronically infected males. The gonadal weights of these seventeen males and others examined at autopsy for the determination of the presence of live trypanosomes were not included in the Tables of gonadal weights.

In addition to determining the presence of live trypanosomes in the testes of males from the above experiments, some infected males from the experimental group described in Table 3 were examined. The gonadal weights of these animals were not included in the statistical calculations. The testes of four animals maintained in constant darkness had regressed to a very small size and contained 50 to 200 trypanosomes/HPF and no spermatozoa. In some cases

Table 4. The appearance of Trypanosoma brucei gambiense in the blood, peritoneal fluid, testes and epididymides after intraperitoneal inoculation into Microtus montanus and the effect of inoculation on the epididymal sperm content

\begin{tabular}{|c|c|c|c|c|c|c|c|c|}
\hline \multirow[t]{2}{*}{ Day } & \multirow{2}{*}{$\begin{array}{c}\text { Animal } \\
\text { No. }\end{array}$} & \multirow{2}{*}{$\begin{array}{l}\text { Tryps. } \\
\text { in } \\
\text { blood }\end{array}$} & \multirow{2}{*}{$\begin{array}{l}\text { Tryps. in } \\
\text { peritoneal } \\
\text { fluid }\end{array}$} & \multicolumn{2}{|c|}{$\begin{array}{c}\text { Tryps. in } \\
\text { testes }\end{array}$} & \multicolumn{2}{|c|}{$\begin{array}{c}\text { Tryps. in } \\
\text { epididymides }\end{array}$} & \multirow{2}{*}{$\begin{array}{c}\quad \text { Sperm. } \\
\text { in } \\
\text { epididymides }\end{array}$} \\
\hline & & & & $R$ & $L$ & $R$ & $L$ & \\
\hline \multirow[t]{2}{*}{1} & $2-12$ & 一 & $1^{+}$ & $\longrightarrow$ & - & 一 & - & + \\
\hline & $\begin{array}{l}4-16 \\
4-7\end{array}$ & $\overline{t^{*}}$ & $\overrightarrow{1+}$ & 二 & 二 & - & - & + \\
\hline \multirow[t]{3}{*}{2} & $5-11$ & 5/HPF & $2^{+}$ & - & $2 / \mathrm{HPF}$ & - & + & + \\
\hline & $4-16$ & $4-6 / \mathrm{HPF}$ & $2^{+}$ & 1/HPF & - & - & + & + \\
\hline & & - & & - & 1/HPF & 一 & - & + \\
\hline \multirow[t]{2}{*}{3} & $3-10$ & - & $1-2^{+}$ & - & - & - & - & + \\
\hline & $6-10$ & - & $1-2^{+}$ & - & - & 一 & $\longrightarrow$ & + \\
\hline \multirow[t]{2}{*}{4} & $4-14$ & $2 / \mathrm{HPF}$ & $1^{+}$ & - & 1/HPF & - & $3 / \mathrm{HPF}$ & + \\
\hline & $3-8$ & $1+$ & - & $1 / \mathrm{HPF}$ & - & - & - & + \\
\hline \multirow[t]{2}{*}{5} & $5-13$ & - & 一 & - & - & - & - & + \\
\hline & $4-18$ & $1 / \mathrm{HPF}$ & - & - & - & 一 & - & + \\
\hline 7 & $6-9$ & $1 / \mathrm{HPF}$ & $1+$ & $1 / \mathrm{HPF}$ & 1/HPF & 二 & 二 & + \\
\hline 10 & $5-13$ & - & $2-3^{+}$ & $1 / \mathrm{HPF}$ & $2-3 / \mathrm{HPF}$ & 一 & $2-3 / \mathrm{HPF}$ & + \\
\hline 13 & $4-5$ & 1/HPF & $3-4+$ & $1 / \mathrm{HPF}$ & $2-3 / \mathrm{HPF}$ & $1 / \mathrm{HPF}$ & - & + \\
\hline 15 & $4-9$ & 2-3/HPF & $2^{+}$ & 10/HPF & $20 / \mathrm{HPF}$ & $6 / \mathrm{HPF}$ & $6 / \mathrm{HPF}$ & 一 \\
\hline 16 & $5-16$ & $2-3 / \mathrm{HPF}$ & $4^{+}$ & $4^{+}$ & $4^{+}$ & $1^{+}$ & $1^{+}$ & Very few \\
\hline \multirow[t]{2}{*}{26} & $2-18$ & 5/HPF & $3-4 / \mathrm{HPF}$ & $3^{3+}$ & $3^{3+}$ & $2-3 / \mathrm{HPF}$ & $3-4 / \mathrm{HPF}$ & - \\
\hline & $5-10$ & $5 / \mathrm{HPF}$ & & $100 / \mathrm{HPF}$ & $50 / \mathrm{HPF}$ & & & + \\
\hline
\end{tabular}

The animals were exposed to 12-hr light/12-hr dark.

HPF, high-power field; $1^{+}(1$ to $20 / \mathrm{HPF}) ; 2^{+}(20$ to $40 / \mathrm{HPF}) ; 3^{+}(40$ to $60 / \mathrm{HPF}) ; 4^{+}$(over 60/HPF). * + denotes presence of trypanosomes or spermatozoa.

the epididymides could not be distinguished. The infected males kept under constant light also had large numbers of trypanosomes in the testes, but the latter were well-developed and spermatozoa were present in both the testes and epididymides.

Time required for the accumulation of trypanosomes in the testes

Approximately fifty males maintained under 12-hr light/12-hr dark were infected with $\mathcal{T}$. $b$. gambiense. One to three animals selected at random were killed every day or two and the testes were examined for the presence of live 
trypanosomes. Even though the trypanosomes appeared in the testes as early as the 2nd day after infection, they did not accumulate there in large numbers until the 15th day (Table 4).

\section{DISGUSSION}

Different photoperiod conditions affected the gonadal weights of male Microtus montanus. This was shown by the actual weights of the gonads of uninfected animals kept under various lighting regimens. Table 1 demonstrates that the gonads of males maintained in constant light were significantly heavier $(P<0.01)$ than the gonads of males kept in constant darkness. This is in agreement with the findings of Pinter (1968). Similar findings are also shown in Table 3 but comparisons between these two Tables should not be made because the animals in Table 1 were younger at death than those in Table 3, and the experiments were carried out at different times of the year in two different locations. The voles in each experimental group represented by each table, however, were approximately the same age.

If the actual gonadal weights of the uninfected animals exposed to 12-hr light/12-hr dark (Table 2) are compared with those of the animals exposed to constant light and those exposed to constant darkness (Table 1), it appears that the $12 \mathrm{hr}$ of alternating illumination reduced or increased testicular weights respectively. If, however, the actual gonadal weights of this same uninfected group of 12-hr light/12-hr dark animals (Table 2) are compared with those of the uninfected group in Table 3, it would appear that $12 \mathrm{hr}$ alternating illumination caused smaller testicular weights than in animals kept in constant darkness. Possibly, the $12 \mathrm{hr}$ alternating light were not enough to demonstrate a significant increase in testicular weights. It is possible that the 46 days in the constant dark chamber, compared to the 70 days in the 12-hr light/ 12-hr dark chamber, was not long enough to cause significant reductions in the actual gonadal weights. If a comparison could be made between Tables 1 and 2 (i.e. experiments performed at the same time and place and all animals of the same age and weight), then the smaller testes of the 12-hr light/12-hr dark animals (Table 2) could indicate that a certain threshold of light is necessary to maintain heavier gonads. Martinet (1963) demonstrated that for Microtus arvalis, male sexual development was maximal with about $15 \mathrm{hr}$ illumination/ day. In female voles ( $M$. agrestis), Breed \& Clarke (1970) found a threshold photoperiod which was greater than $12 \mathrm{hr}$ and less than $14 \mathrm{hr}$. Also, Gaston \& Menaker (1967) demonstrated that the testes of adult hamsters needed at least $12 \frac{1}{2} \mathrm{hr}$ light per day to maintain spermatogenesis. From the data in Table 3, it would appear paradoxically that the gonads of animals maintained in constant darkness were approximately the same size as the gonads of Microtus maintained in constant light (Table 1). Again, however, since all experimental groups were not maintained in the same chamber at the same time of year, and the animals were not the same age, the comparison of data from the different tables should not be stressed. Furthermore, as far as laboratory $M$. montanus is concerned, older animals have been shown to have heavier testes (Pinter, 1968) and all our older voles were heavier in weight than the younger 
animals. It should be pointed out again, however, that constant light did result in heavier gonads than did constant darkness.

Certain trypanosomes have shown a predilection for the testes of some mammalian hosts such as rabbits and guinea-pigs (Heisch et al., 1970). These workers found that animals inoculated intratesticularly developed atrophied tubules with complete absence of spermatocytes, an increase of round cell infiltration of the interstitial tissues, followed by interstitial fibrosis and atrophy. In the present investigation, $T . b$. gambiense was clearly shown to have a predilection for the testes of $M$. montanus even though inoculation was intraperitoneal.

The testes of infected voles exposed to $12-\mathrm{hr}$ light/12-hr dark atrophied and weighed less $(P<0 \cdot 10)$ than those of uninfected animals under the same lighting regimen (Table 2). If the normalized weights for this group (Table 2) are considered, the weight reduction is more significant $(P<0 \cdot 02)$ since infected animals had heavier body weights due to accumulation of excess body fluid. The results are therefore biased in favour of reduced testicular weights for the infected animals.

Infected voles maintained in constant darkness (Table 3) also had atrophied testes which weighed significantly less than those of uninfected animals. Infected animals in constant darkness (Table 3) had heavier testes than uninfected males in constant darkness (Table 1), though, as already mentioned, comparisons of data from the different Tables should not be stressed.

Infected animals kept in constant light did not exhibit significant weight reductions compared to the uninfected males also maintained in constant light (Table 3). The normalized weights in Table 3 show a significant reduction $(P<0.02)$ for the infected voles under constant light. Again, the heavier body weights give results which are biased in favour of the smaller testes for the infected animals. Although infected males in constant light maintained normal testicular weights when compared to the uninfected males in the same experiment (Table 3), the infected males exposed to 12-hr light/12-hr dark and infected males kept in constant darkness had smaller testes than the uninfected control group. These results show that photoperiod can modify the effects of a T. b. gambiense infection in $M$. montanus.

While infected males in constant light maintained active spermatogenesis, no spermatozoa were found in infected animals kept in constant darkness. All of these animals were infected with the same inoculum, were under the experimental regimen at the same period of time, and were approximately the same age. All animals were sexually mature and had well-developed testes at the time of infection. After only 21 days of infection, especially in those animals in constant darkness, the testes had atrophied. Photoperiod, therefore, can affect sperm viability in the infected animals. Long lighting periods (i.e. constant light) during infection in $M$. montanus can counteract the effects of a $T . b$. gambiense infection on testicular weights and sperm production.

Short-term infected males maintained under $12 \mathrm{hr}$ alternating illumination are able to impregnate females, resulting in the production of live offspring. From preliminary results, however, it appears that the reproductive capacity of infected males is reduced. This could be due to the damage caused by the 
trypanosomes in the testes and/or possible changes in mating behaviour since the trypanosomes also accumulate in the brains of $M$. montanus producing neurological symptoms (Seed \& Negus, 1970; Seed \& Khalili, 1971).

In a consideration of the testicular accumulation of trypanosomes in $M$. montanus inoculated intraperitoneally, we propose the following mechanism. Although high parasitaemia has not been found in the peripheral blood of Microtus (Seed \& Negus, 1970), some trypanosomes do enter the peripheral circulation, and could reach the testes by the internal spermatic artery. A few appear in the testes 1 to 2 days after infection and by the 15 th day their numbers have increased enormously (Table 4). It is possible that the trypanosomes are responding to the biochemically rich environment of the testes, i.e. glucose (Annison, Scott \& Waites, 1963; Free, Massie \& VanDemark, 1969; Fouquet, 1971). The response by the trypanosomes to the cooler environment of the testes has been ruled out very recently. Mature $M$. montanus made cryptorchid experimentally and subsequently infected with $T . b$. gambiense have, at autopsy, large numbers of the trypanosomes accumulated in the testes 15 days after infection (P. U. Ashman and T. M. Smith, unpublished results).

In a consideration of the pathological effects of the trypanosomes on the males gonads, both spermatogenesis and hormone production are adversely affected and the testes atrophy (Heisch et al., 1970). It is also possible, since large numbers of trypanosomes accumulate in the brains of chronically infected Microtus and neurological symptoms occur (Seed \& Negus, 1970; Seed \& Khalili, 1971), that nerve centres such as the pineal, hypothalamus and pituitary may also be affected, resulting in changes in the testes. The involvement of these centres is also suggested by the fact that infected animals kept in constant light can maintain normal testicular weights and produce spermatozoa, while the voles exposed to 12-hr light/12-hr dark have reduced sperm production and those in constant darkness have no spermatozoa. All of these factors may act synergistically in producing the atrophied testes in the animals exposed to 12-hr light/12-hr dark and to constant darkness.

We predict that regardless of how the disease is contracted (bite of tse-tse fly or by syringe passage), any mammals, including man, chronically infected with the pathogenic African trypanosomes have these organisms in the testes.

\section{ACKNOWLEDGMENTS}

This investigation was supported by N.S.F. Grant No. GB-7401 and was also aided by a Grant-in-Aid of Research to P.A. from the Society of the Sigma Xi. The senior author, was supported by a National Institute of Health Fellowship No. 5-F01-GM-43,611 while on leave of absence from Xavier University of Louisiana. This report is in part an abstract from a thesis submitted by the senior author to Tulane University in partial fulfilment of the requirements for the degree of Doctor of Philosophy.

\section{REFERENCES}

Annison, E. F., Scott, T. W. \& WAites, G. M. H. (1963) The role of glucose and acetate in the oxidative metabolism of the testis and epididymis of the ram. Biochem. $\mathbf{7 . 8 8 , 4 8 2 .}$

Ashman, P. U. \& Seed, J. R. (1973a) Biochemical studies in the vole, Microtus montanus. I. The daily variation of hepatic glucose-6-phosphatase and liver glycogen. Comp. Biochem. Physiol. 45, 365. 
Ashman, P. U. \& Seed, J. R. (1973b) Biochemical studies in the vole, Microtus montanus. II. The effects of a Trypanosoma brucei gambiense infection on the diurnal variation of hepatic glucose-6-phosphatase and liver glycogen. Comp. Biochem. Physiol. 45, 379.

Breed, W. G. \& Clarke, J. R. (1970) Effect of photoperiod on ovarian function in the vole, Microtus agrestis. J. Reprod. Fert. 23, 189.

GrucA, A. (1933) La dourine. Bull. Off. int. Epizoot. 7, 168.

Davis, B. D., Dulbecco, R., Eisen, H. N., Ginsberg, H. S. \& Wood, W. B., JR (1967) Microbiology. Harper \& Row, New York.

Domlescu, G. G. (1938) Contributiuni la studiul transmisiunei experimentale a durinei Europene-tulpina româneasca. Thesis, Bucarest. [Vet. Bull., Weybridge, (1941) 11, 159. Abstr.]

Fouquet, J. P. (1971) Secretion of free glucose and related carbohydrates in the male accessory organs of rodents. Comp. Biochem. Physiol. 40, 305.

Free, M. J., Massie, E. D. \& VanDemark, N. L. (1969) Glucose metabolism by the cryptorchid rat testis. Biol. Reprod. 1, 354.

Gaston, S. \& Menaker, M. (1967) Photoperiodic control of hamster testis. Science, N. Y. $158,925$.

HaIG, D. A. \& Lund, A. S. (1948) Transmission of the South African strain of dourine to laboratory animals. Onderstepoort 7. vet. Sci. Anim. Ind. 23, 59.

Heisch, R. B., Killick-Kendrick, R., GuY, M. W. \& Dorrell, J. (1970) The development of trypanosomes, leishmaniae and ascitic tumour cells in the testicles of laboratory animals. Trans. $R$. Soc. trop. Med. Hyg. 64, 679 .

Martinet, L. (1963) Etablissment de la spermatogénèse chez le campagnol des champs (Microtus arvalis) en fonction de la durée quotidienne d'éclairement. Annls Biol. anim. Bioch. Biophys. 3, 342.

Molyneux, D. H. (1972) Isolation of Trypanosoma (Trypanozoon) brucei gambiense by the intratesticular inoculation technique and the biology of the parasites after isolation. Trans. R. Soc. trop. Med. Hyg. 66, 338.

Pinter, A. J. (1968) Effects of diet and light on growth, maturation, and adrenal size of Microtus montanus. Am. 7. Physiol. 215, 461.

Pinter, A. J. \& Negus, N. G. (1965) Effects of nutrition and photoperiod on reproductive physiology of Microtus montanus. Am. J. Physiol. 208, 633.

Seed, J. R., Baquero, M. A. \& Duda, J. F. (1965) Inhibition of hexose and glycerol utilization by 2-deoxy-d-glucose in Trypanosoma gambiense and Trypanosoma rhodesiense. Expl Parasit. 16, 363.

SEed, J. R. \& GAM, A. A. (1966) Passive immunity to experimental trypanosomiasis. F. Parasit. 52, 1134.

SEed, J. R. \& Kralini, N. (1971) The changes in locomotor rhythms of Microtus montanus infected with Trypanosoma gambiense. J. interdiscip. Cycle Res. 2, 91.

Seed, J. R. \& Negus, N. C. (1970) Susceptibility of Microtus montanus to infection by Trypanosoma gambiense. Lab. Anim. Care, 20, 657.

Soldini, M. (1939) Procédé pratique et rapide de diagnostic expérimental de la dourine. Bull. Soc. Path. exot. 32, 334.

Uhlenhuth, P. \& Emmerich, E. (1913) Ueber das Verhalten des Kaninchenhodens bei experimenteller Trypanosomen- und Spirochäteninfektion. Dt. med. Wschr. 39, 642.

VestergaARD, B. F. \& Scherer, W. F. (1971) An RNA viral infection of hamster testes and uteri resulting in orchitis and effects on fertility and reproduction. Am. 7. Path. 64, 541 . 